3. Schrander-Stumpel CT, Spruyt L, Curfs LM, et al. Kabuki syndrome: clinical data in 20 patients, literature review, and further guidelines for preventive management. Am J Med Genet A 2005;132:234-43.

4. Adam MP, Hudgins L. Kabuki syndrome: a review. Clin Genet 2005;67:209-19.

5. Iida T, Park S, Kato K, et al. Cleft palate in Kabuki syndrome: a report of six cases. Cleft Palate Craniofac J 2006;43:756-61.

\section{Hydrocele of the Canal of Nuck in a Female Adult}

Kwang Seog Kim, Jun Ho Choi, Hong Min Kim, Kyung Pil Kim, Yu jin Kwon, Jae Ha Hwang, Sam Yong Lee

Department of Plastic and Reconstructive Surgery, Chonnam National University Medical School, Gwangju, Korea

Correspondence: Kwang Seog Kim

Department of Plastic and Reconstructive Surgery, Chonnam National University Medical School, 42 Jebong-ro, Dong-gu, Gwangju 61469, Korea Tel: +82-62-220-6363/6352, Fax: +82-62-220-6357

E-mail: pskim@chonnam.ac.kr

No potential conflict of interest relevant to this article was reported.

Received: 14 Jun $2016 \bullet$ Revised: 22 Aug 2016• Accepted: 31 Aug 2016 pISSN: 2234-6163・ elSSN: 2234-6171

http://dx.doi.org/10.5999/aps.2016.43.5.476 Arch Plast Surg 2016:43:476-478

Copyright (C) 2016 The Korean Society of Plastic and Reconstructive Surgeons This is an Open Access article distributed under the terms of the Creative Commons Attribution Non-Commercial License (http://creativecommons.org/licenses/by-nc/4.0/ which permits unrestricted non-commercial use, distribution, and reproduction in any medium, provided the original work is properly cited.

The canal of Nuck is a small evagination of the parietal peritoneum, which is attached to the uterus by the round ligament through the internal inguinal ring into the inguinal canal. This structure is homologous to the processus vaginalis of the male anatomy [1].

Although the canal of Nuck normally disappears without a trace in the first year of life, it can cause an

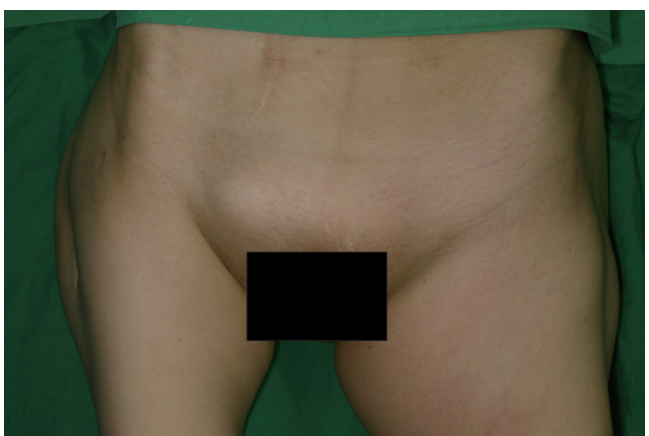

indirect inguinal hernia or hydrocele of the canal of Nuck when, in rare cases, it does not disappear completely. Hydrocele of the canal of Nuck is a rare disease that occurs in the inguinal area or labium as a painless edema before adolescence [2]. We report the case of a hydrocele of the canal of Nuck in a female adult.

A 51-year-old female patient visited our hospital with a complaint of $7 \times 4-\mathrm{cm}$ painless swelling in her right groin that had first appeared 4 months previously and had grown in size since then. The mass had not been present in infancy or adolescence. The patient showed severe atrophic changes in her right thigh, groin, and buttocks due to poliomyelitis and had undergone tendon transfer surgery to fix the tendon of the right external oblique muscle to the greater trochanter of the right femur 20 years prior. In addition, a 20 -cm oblique scar was observed in the right lower abdomen (Fig. 1). Although the patient did not present with clinical symptoms such as fever, nausea, or vomiting, the swelling in the right groin protruded in the standing position and disappeared in the lying position. Thus, abdominal computed tomography (CT) was performed to distinguish the swelling from hernia. An abdominal CT scan showed a $7.1 \times 3.8$-cm cystic mass in the right inguinal canal, and lymphangioma or hydrocele of the canal of Nuck was suspected. Abdominal magnetic resonance imaging (MRI) was performed to examine the communication between the cystic mass and peritoneal cavity, and the precise anatomy around the cystic mass. It was found that the cystic mass in the inguinal canal included thin septa, and hydrocele of the canal of Nuck was suspected because of the low and high signal intensities observed on the $\mathrm{T}_{1}$ - and $\mathrm{T}_{2}$-weighted images, respectively. Only the wall and septa were contrast-enhanced (Fig. 2). The cystic mass was examined histopathologically after high ligation and hydrocelectomy were performed. Then, a diagnostic test was performed by using a fluid sample from the mass (Fig. 3).

The histopathological examination revealed that the tissue was positive for creatine kinase, Wilms tumor protein 1 (WT-1), and D2-40, as well as mesothelial cells (Fig. 4). According to the results of the diagnostic test, the fluid included cellular components similar to those of peritoneal fluid. Based on the imaging, histopathology, and diagnostic testing, we made a diagnosis of hydrocele of the canal of Nuck.

The canal of Nuck was first described by a Dutch 
anatomist, Anton Nuck, in 1691. It is homologous to the processus vaginalis peritonei in male fetuses, where the parietal abdominal wall evaginates when the testis descends to the scrotum.

If the canal of Nuck as normal evagination of the parietal abdominal wall does not disappear when the uterus passes through the inguinal canal along the ligamentum teres uteri in female fetuses, it causes an indirect inguinal hernia or hydrocele of the canal of Nuck.

The canal of Nuck derived from the abdominal wall is divided into two layers. The outer wall histologically consists of a fibrous form of various thicknesses, including smooth muscle fibers, and the inner wall consists of single-layered mesothelial cells. When the secretion and absorption of fluid become unbalanced in the secretory membrane on the inner wall, hydrocele of the canal of Nuck occurs due to swelling of the pouch. The hypersecretion and malabsorption of the secretory membrane can be caused by infection, injury, or inappropriate lymphatic drainage, the latter of which is usually multiple. In the present case, the patient showed severe atrophic changes in the right groin, buttocks, and thigh due to poliomyelitis and underwent tendon transfer surgery for the tendon of the right external oblique muscle. However, we have not been able to find any report in the literature suggesting that patients with poliomyelitis are susceptible to hernia or hydrocele of the canal of Nuck.

Inguinal swelling in women should be distinguished from indirect inguinal hernia, tumors (lipoma, leiomyoma, and sarcoma), cyst, abscess, and lymphadenitis. In most cases, the canal of Nuck should be distinguished from inguinal hernia, and hernia should be strongly suspected when bowel sounds are heard from the swelling.

In general, the canal of Nuck is hypoechoic or

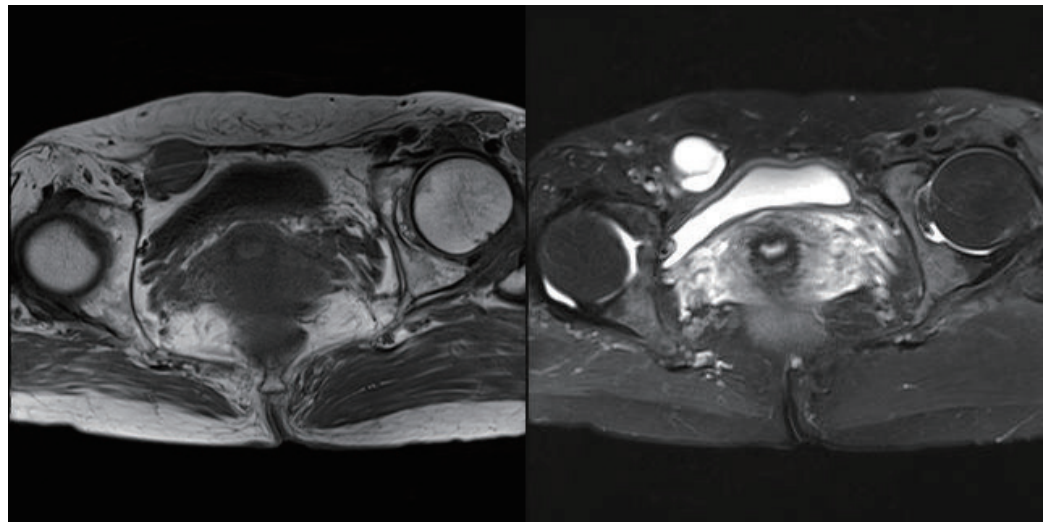

Fig. 2.

Imaging examination results. The magnetic resonance image shows the $7 \times 4.5 \times 2.5-\mathrm{cm}$ mass with a relatively well-defined margin in the right inguinal canal, and the lesion includes thin septa inside. The lesion showed lowand high-signal intensity on the $T_{1}$ - and $T_{2}$-weighted images and signs of cyst (or hydrocele) of the canal of Nuck because the wall and septa are contrast-enhanced.

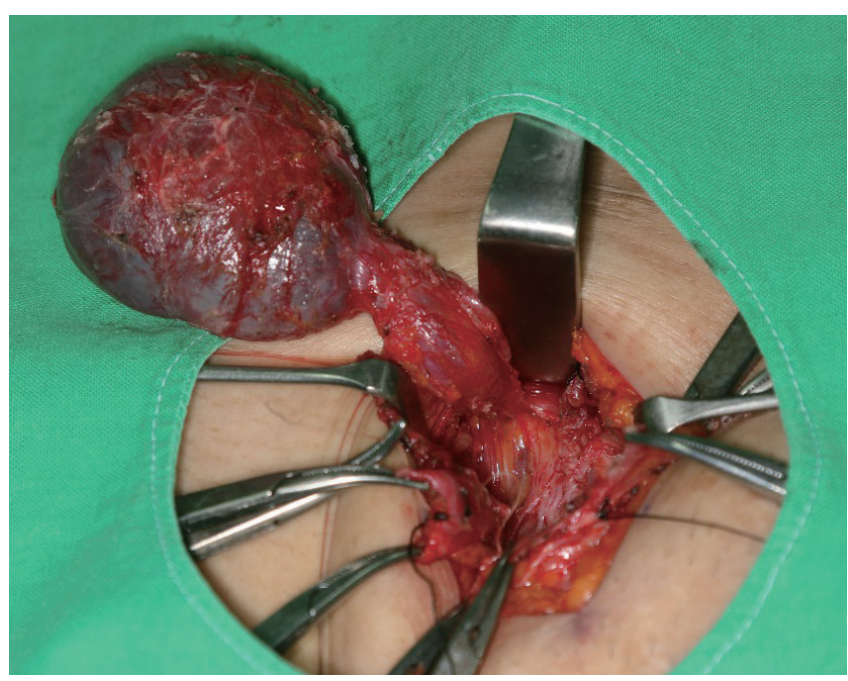

Fig. 3.

Intraoperative photograph. An intact cyst can be observed in the canal of Nuck.

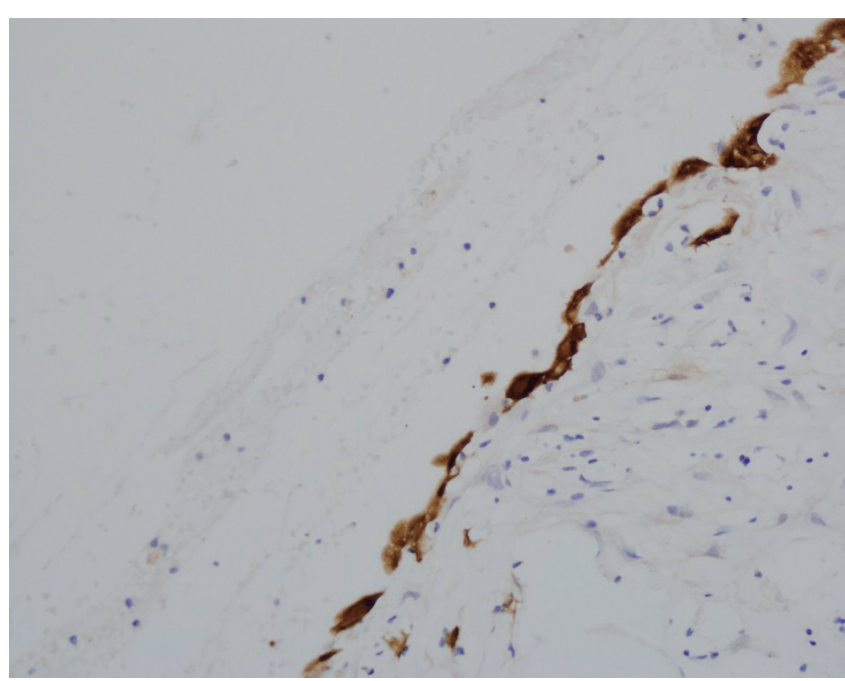

Fig. 4.

Histopathological examination image. The mesothelial cells show positive calretinin staining on the inner wall of the cyst $(\times 200)$. 
anechoic and comma- or mushroom-shaped unilocular on ultrasonography. In rare cases, it shows signs of a multilocular cystic mass with linear septa [3]. Although the CT scan showed the hydrocele of the canal of Nuck in the form of a homogenous fluidfilled unilocular cyst extending to the labia, its communication with the abdominal cavity could not be determined. MRI revealed well-defined, thinwalled, sausage-shaped cystic lesions in the hydrocele of the canal of Nuck. Low- and high-signal intensities were observed on the $\mathrm{T}_{1}$ - and $\mathrm{T}_{2}$-weighted images, respectively [2].

The final diagnosis was made during surgery and confirmed by histopathological examination. The standardized therapeutic approach is to surgically remove edema and to ligate the processus vaginalis peritonei. Due to the rarity of hydrocele of the canal of Nuck, there are no reports on the recurrence rate of masses or simultaneous occurrence on the opposite side. The hernial sac can include peritoneal fluid, omental fat, bowel loops, the ovary, the fallopian tube, or the urinary bladder in the inguinal canal. Therefore, surgeons can avoid causing damage in the process of examining the anatomy around the inguinal canal by using preoperative imaging.

Despite the fact that hydrocele of the canal of Nuck occurs mainly in adolescence, we strongly suspected hydrocele of the canal of Nuck in this case based on the clinical symptoms and imaging diagnosis, and confirmed the diagnosis by surgical exploration without delay. This case suggests that hydrocele of the canal of Nuck should be included in the differential diagnosis of masses occurring in the inguinal area in adult females.

\section{References}

1. Anderson CC, Broadie TA, Mackey JE, et al. Hydrocele of the canal of Nuck: ultrasound appearance. Am Surg 1995;61:959-61.

2. Manjunatha Y, Beeregowda Y, Bhaskaran A. Hydrocele of the canal of Nuck: imaging findings. Acta Radiol Short Rep 2012;1. http://dx.doi.org/10.1258/ arsr.2012.110016.

3. Akkoyun I, Kucukosmanoglu I, Yalinkilinc E. Cyst of the canal of nuck in pediatric patients. $\mathrm{N}$ Am J Med Sci 2013;5:353-6.

\section{Acute Febrile Neutrophilic Dermatosis after Deep Inferior Epigastric Perforator Flap Breast Reconstruction}

Michael W. Chu' ${ }^{1}$, Julia A. Cook ${ }^{1}$, Alexes Hazen ${ }^{2}$

${ }^{1}$ Division of Plastic and Reconstructive Surgery, Indiana University, Indianapolis, IN; ${ }^{2}$ Department of Plastic and Reconstructive Surgery, Institute of Reconstructive Plastic Surgery, New York University Medical Center, New York, NY, USA

Correspondence: Michael W. Chu

Division of Plastic and Reconstructive Surgery, Indiana University, 545 Barnhill Drive, \#232, Indianapolis, IN 46202, USA

Tel: +1-317-274-3636, Fax: +1-317-278-8746

E-mail:dr.michael.chu@gmail.com

No potential conflict of interest relevant to this article was reported.

Received: 13 Feb 2016 • Revised: 29 Mar 2016 • Accepted: 19 Apr 2016 pISSN: 2234-6163・ elSSN: 2234-6171

http://dx.doi.org/10.5999/aps.2016.43.5.478

Arch Plast Surg 2016;43:478-481

Copyright (C) 2016 The Korean Society of Plastic and Reconstructive Surgeons This is an Open Access article distributed under the terms of the Creative Commons Attribution Non-Commercial License (http://creativecommons.org/licenses/by-nc/4.0/ which permits unrestricted non-commercial use, distribution, and reproduction in any medium, provided the original work is properly cited.

Acute febrile neutrophilic dermatosis (AFND), or Sweet syndrome, is a rare neutrophil-mediated hypersensitivity reaction of unknown etiology. There are four sub-classifications of AFND: (1) idiopathic,

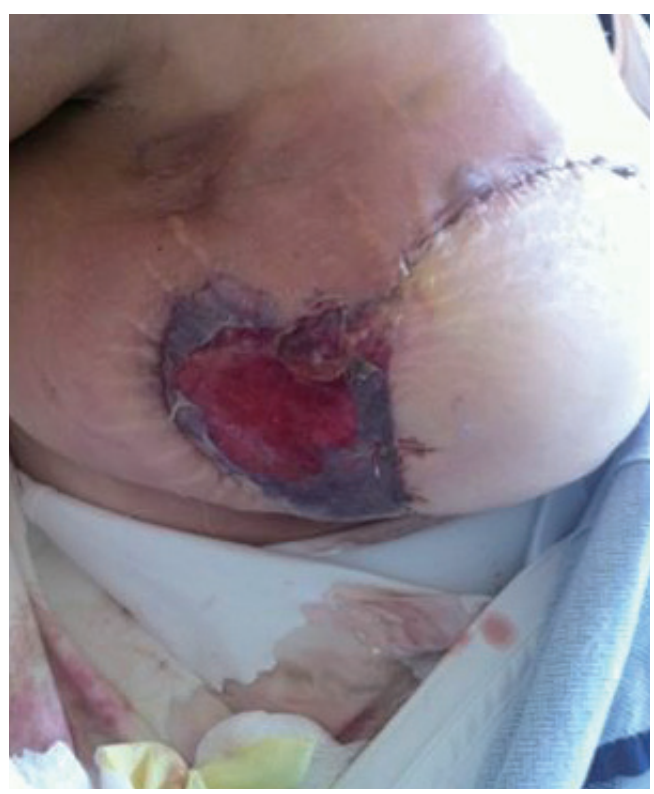

Fig. 1.

Postoperative day three: the neutrophilic dermatosis lesions are seen in evolution, ranging from violaceous papules to partial-thickness skin loss and exposed dermis. Of note, there was no purulence or malodorous drainage. 